\title{
A macroergonomia na melhoria das condições de trabalho com ênfase nos aspectos de liderança: Estudo de caso com AMT em um restaurante
}

\author{
How macroergonomics can contribute to improvements in working \\ conditions with emphasis on leadership: A case study \\ with $A M T$ in a restaurant
}

\author{
Souza, Juliana de; Especilista; \\ Universidade Estadual de Londrina \\ juliana.souza88@hotmail.com \\ Sampaio, Cláudio Pereira de; Mestre \\ Universidade Federal do Paraná \\ qddesign@hotmail.com
}

\begin{abstract}
RESUMO
A Macroergonomia é baseada em um método participativo, no qual o público envolvido no processo de trabalho contribui para que as intervenções que se façam necessárias tenham uma maior assertividade, pois reduz a margem de erros na sua criação e tem melhora e aceitação porque foi construído junto com os trabalhadores. Por meio deste estudo buscou-se verificar como a liderança influencia no processo de melhoria do ambiente de trabalho no campo da macroergonomia. As visões dos colaboradores e do gerente foram confrontadas para avaliar os pontos críticos da gerência e propor ações de melhoria. Os resultados permitiram concluir os conceitos, técnicas e ferramentas da macroergonomia somente podem ser aplicados e implementados em sua plenitude quando são reconhecidos pelo Líder como indispensáveis para o bem-estar dos trabalhadores e para a melhoria do seu desempenho. Para isto, o gerente deve apresentar os requisitos mínimos para uma boa liderança.
\end{abstract}

Palavras-chave: Liderança, Macroergonomia, Restaurantes.

\begin{abstract}
The macroergonomics is based on a participatory approach, in which the public involved in the work process helps to ensure that interventions are necessary to have a more assertive because it reduces the margin of error in its creation and has improved and acceptance because it was built along with workers. Three capstan of this study tried to determine how leadership influences the process of improving the working environment in the field of macroergonomics. The views of employees and manager were compared to evaluate the critical management and propose actions for improvement. The results showed the concepts, techniques and tools macroergonomics can only be applied and implemented in its entirety when they are recognized as indispensable by the Leader for the welfare of workers and to improve its performance. For this, the manager must provide the minimum requirements for good leadership.
\end{abstract}

Keywords: Leadership, Macroergonomics, Restaurants.

\section{Introdução}

A liderança é um fator relevante nas organizações, e é considerada uma vantagem competitiva na estratégia das empresas. O seu impacto no desempenho corporativo já é pesquisado desde os anos 60 por diversos estudiosos, como Warren Bennis, John Kotter e Rensis Likert, entre outros, tanto na 
atuação dos altos executivos quanto dos gerentes de nível médio.

Por outro lado, a macroergonomia é um campo de estudo recente, que traz para as empresas a possibilidade de se avaliar a estrutura organizacional de forma holística e participativa, detectando possibilidades de melhoria que vão além dos aspectos puramente ergonômicos. A macroergonomia parte da visão integrada da organização, passa pelo processo até chegar ao posto de trabalho. Para isso, tem como uma das premissas básicas o envolvimento dos colaboradores, tanto executivos e gerentes quanto os funcionários subordinados.

Nesse sentido, este trabalho busca demonstrar como a abordagem macroergonômica pode ser útil para aprimorar o desenvolvimento daqueles que estão em papéis de liderança nas empresas, notadamente os gerentes que estão em contato direto com os funcionários. Para isso, o estudo inclui o uso de ferramentas de coleta e análise de dados usados na macroergonomia, como entrevistas e questionários, seguidos de tabulação dos dados e sua análise.

Como resultados, discute-se a divergência entre as visões do gerente e dos funcionários como um dos pontos mais significativos do trabalho, pois indica espaços de melhoria. São apontados os aspectos a serem aprimorados pelo líder, com o objetivo de ampliar a sua competência de liderança, indo além do papel gerencial a que o mesmo está vinculado.

Neste sentido, este artigo tem como objetivos principais identificar a visão do gerente sobre o seu desempenho em diferentes aspectos relacionados à liderança; identificar a visão dos colaboradores sobre o desempenho do gerente em termos de liderança; confrontar as duas visões, apontando pontos críticos a serem melhorados, e propor ações de melhoria a partir dos pontos críticos analisados.

\section{Macroergonomia: Definição e Conceito}

A Macroergonomia é baseada em um método participativo, no qual o público envolvido no processo de trabalho contribui para que as intervenções que se façam necessárias tenham uma maior assertividade, pois reduz a margem de erros na sua criação e tem melhora e aceitação porque foi construído junto com os trabalhadores (GUIMARÃES, 2006).

Sua forma de avaliação é por meio de uma abordagem única dos quatro subsistemas principais, incluindo assim as variáveis ambientais, tecnológicas e interpessoais que interferem nas interações sistêmicas entre os indivíduos e os dispositivos de trabalho, como forma de aperfeiçoar a produtividade (MEDEIROS, 2005; KLEINER, 1998).

\section{Macroergonomia: Breve histórico}

A história da Macroergonomia surgiu nos Estados Unidos, como ação rápida em resposta ao aumento de venda de produtos industriais, fazendo que aconteça uma mudança necessária. Segundo IIDA (2005), a Macroergonomia surge como desenvolvimento na interação homem maquina ambiente organização ocorrendo num nível macro. Dessa maneira, seus conceitos são globalizados desde o início dos processos. Os subsistemas tecnológico, pessoal e sistemas organizacionais, reduzindo custos e buscando a melhoria do conforto e produtividade dos colaboradores. Os aspectos físicos ambientais são construção do ambiente, temperatura, ventilação, iluminação e ruído.

Segundo Guimarães (2006), o AMT - Análise Macroergonômica do Trabalho, é ?um método de análise que pode ser utilizado tanto pelo pesquisador Ergonomista como pelos representantes das empresas responsáveis pela implantação das ações ergonômicas (...). Também é importante ressaltar a dimensão de seu foco de ação que parte da organização, passa pelo processo até chegar ao posto de trabalho e principalmente, o seu caráter eminentemente participativo (...)".

A participação dos trabalhadores na reestruturação do ambiente de trabalho, somada à avaliação de especialista, faz-se de extrema importância para a incorporação das mudanças necessárias e para a melhoria das condições dentro dos sistemas. 


\section{Liderança e Gerência}

\section{Conceito de Liderança}

A liderança não representa apenas a função do líder, mas é um processo que envolve principalmente o atendimento de objetivos mútuos. Requer, com isso, a cooperação por parte de outras pessoas (HOLLANDER, 1978). Na história administrativa a liderança não foi pesquisada como fator produtivo, mas tradicionalmente conceituada no aspecto de traços de personalidade, estilo de comportamento e fatores contingenciais. Com isso, houve ênfase na personalidade decorrente das qualidades pessoais do administrador como seu temperamento, caráter e relacionamento humano com sua inteligência (BERGAMINI; 1994; AUBERT, 1991; YULK 1989).

Chiavenato (1999) comenta que "para dirigir, não basta apenas dar ordens e instruções, comunicar e motivar". Para ele, estar na linha de frente impõe responsabilidade determinação e muita paciência em liderar pessoas. Nesse sentido, um dos grandes desafios do líder é inovar a cada dia na motivação dos seus colaboradores (BENNIS, 1996).

Kotter (1990) citado por Kennedy (2000), a partir de estudos em diversas corporações americanas, identificou como principais tarefas do líder:

- Estabelecer direção, visão e estratégia para o negócio;

- Alinhar as pessoas para a direção escolhida, por meio da compreensão e aceitação;

- Motivar e inspirar as pessoas, apelando para necessidades, emoções e valores básicos, muitas vezes desconhecidos.

Segundo ele, algumas características básicas encontradas nos líderes são:

- Nível de energia acima da média;

- Motivação interior associada a altos padrões pessoais com tendência ao aperfeiçoamento contínuo, insatisfação com o status quo;

- Habilidades intelectuais acima da média, como ao absorver e processar diversas informações;

- Saúde mental ou emocional;

- Integridade.

Segundo Covey (1989), não existe meio fácil e rápido de desenvolver líderes. Os humanos devem aprender pela vivência: nunca deixar de estudar; nunca menosprezar novos pensamentos filosóficos, novas ideias, novos procedimentos ou novos métodos não importam de quem ou de onde tenham sido copiados ou recolhidos. As pessoas que pautam suas vidas em princípios são continuamente instruídas por suas experiências. Leem, procuram treinamento, assistem a aulas, escutam os outros, aprendem com os olhos e ouvidos bem abertos (COVEY, 1989).

Oliveira (2000) descreve a liderança servidora como a descoberta mais recente do mundo organizacional, capaz de tornar o ambiente de trabalho mais humano e mais produtivo. Autores como James C. Hunter tem explorado bastante este tema, com trabalhos que fundem elementos de administração e psicologia comportamental com ideias próximas da literatura autoajuda.

\section{Tipos de Liderança}

Os estudos sobre tipos de liderança e sua influência nas empresas são estudados há bastante tempo, e tem como um dos precursores o psicólogo Rensis Likert (1961). Seus estudos da década de 60 identificaram diferentes tipos de liderança, e com isso, ele propôs quatro estilos administrativos: autoritário explorador, autoritário benevolente, consultivo e participativo.

De forma semelhante, conforme Chiavenato (1999) e Robbins (2005) são comumente encontrados três tipos liderança nas empresas: autocrática, liberal e democrática, e que comportam características diferenciadas e de certo modo complementares para a qualidade gerencial. Estas 
Souza, Juliana de; Pereira, Cláudio Sampaio

podem ser assim descritas:

- Autocrática: É também chamada liderança autoritária, sua principal característica é a de que líder é quem toma as decisões e impões as ordens aos subordinados, sem querer explicá-la ou justificá-las. Os subordinados não têm liberdade de atuação. As pesquisas têm demonstrado que a liderança autocrática cria sentimento de insatisfação nas pessoas, alienação quanto ao trabalho e falta de motivação. Isto faz com que este tipo de liderança seja apenas utilizado em trabalho simples, rotineiro e repetido.

- Liberal: Omite-se, não se impõe quando os subordinados se tornam os donos da situação. Há uma completa e total liberdade de atuação para os subordinados e nenhum controle sobre seu trabalho. E, todavia os objetivos do trabalho também não são explicados. As pesquisas sugerem que a liderança liberal também não cria sentimento de desorientação, de insatisfação e falta de cooperação entre as pessoas.

- Democrática: É o tipo de liderança que fica no meio termo entra a autocrática e liberal, evitando as desvantagens de ambas, e com caráter participativo. $O$ assunto é debatido com os subordinados que fazem sugestões que, se viáveis, são aceitáveis pelo líder.

Desde os estudos de Likert (1961), já era possível observar que a liderança democrática conduz a sentimentos de participação satisfação, envolvimento pessoal, espírito de equipe e de colaboração, além de elevada motivação para resultados. Dais sua utilização intensiva em que quase todos os tipos de atividade. Este tipo de líder seria, pelo caráter participativo, o mais indicado para o uso da macroergonomia, que prescinde do envolvimento dos funcionários para sua realização de um trabalho eficaz de AMT.

\section{Conceito e função de gerência}

A palavra gerência parece ser originária de um antigo verbo francês, ménager, que em seu sentido bem arcaico significa gerir e administrar a propriedade. Refere-se a um cargo que ocupa um dirigente de uma empresa, por exemplo, que tem dentro de suas múltiplas funções, representa uma sociedade frente a terceiros e coordena todos os recursos através do processo de planejamento, organização, direção e controle a fim de atingir objetivos estabelecidos (FREEMAN, 1995; SISK \& SVERDLIK, 1979).

Quando a gerência é estudada como uma disciplina acadêmica é importante considerá-la como um processo, por ser analisada e descrita em termos de várias funções fundamentais (FREEMAN, 1995; SISK \& SVERDLIK,1979).

\section{A relação entre gerência e liderança}

As dimensões de liderança e gerência parecem ter relação entre si muito complexas e que precisa ser explorada. Elas não devem ser confundidas. Um bom gerente deve ser necessariamente um bom líder, mas o líder nem sempre é um gerente (CHIAVENATO, 1994).

A empresa precisa de líderes em todos os seus níveis hierárquicos, mas é na gerência que se encontra o ponto crucial da liderança. A gerência funciona como decodificadora dos objetivos fixados pela alta direção, transformando-os em planos e programas. Assim, a gerência direciona e conjuga liderança, motivação e esforços dentro do grupo, lidando então com pessoas. E ao lidar com pessoas, surge a principal ferramenta gerencial que é a liderança (CHIAVENATO, 1994).

O gerente pode apoiar-se completamente na autoridade do seu cargo ou adotar um estilo de comportamento mais participativo que tenha decisão conjunta com seus subordinados. Pode adotar um estilo autocrático e impositivo ou democrático e participativo para conseguir que as tarefas sejam realizadas pelas pessoas (FREEMAN, 1995; SISK e SVERDLIK, 1979).

O administrador é a pessoa que tem sob sua responsabilidade o desempenho de uma ou mais 
pessoas de uma organização. Ele consegue resultados por meio de sua empresa e das pessoas que nela trabalham. Para isso, planeja, organiza, dirige, controla os diversos recursos visando à realização de objetivos específicos (SCHERMERHORN Jr, HUNT e OSBORN, 1999).

Ocorre que o gestor faz as coisas por meio das pessoas, motivo pelo qual elas ocupam posições fundamentais nos negócios de todas as organizações. São normalmente chamados de subordinados, funcionários, colaboradores, parceiros ou empreendedores internos. 0 rumo e a direção das organizações são ditados pelo administrador, que lidera as pessoas e decide como os recursos organizacionais devem ser colocados e usados na consecução dos objetivos da organização. São atividades que se aplicam em qualquer nível da empresa (ROBBINS, 2000).

A forma como os gerentes agem com os seus subordinados é influenciada pela ideia que o gestor tem deles, além de sua própria subjetividade e das circunstâncias do ambiente. Preocupadas com a defasagem conceitual de seus gerentes, muitas empresas começaram a treiná-los com as mais modernas técnicas de liderança disponíveis no mercado (KOYS \& COTIIS, 1991).

O gestor pode assumir os mais variados papéis que a situação exigir. Em alguns, ele é um chefe enérgico; em outros, ele é brando e democrático. Em certos momentos ele delega, em outros determina. Em algumas situações procura compartilhar, em outras convencerem. Em casos específicos mostra-se ativo, participativo, enquanto em outros desaparece por algum tempo, mostrando-se distante e ausente (CARBONE, 1992).

Chiavenato (1994) afirma que na prática, o administrador utiliza os três estilos de liderança de acordo com a tarefa a ser executada, as pessoas e a situação. $O$ administrador tanto manda cumprir ordens como sugere aos subordinados a realização de certas tarefas, ou ainda os consulta antes de tomar alguma decisão. $O$ desafio está em saber quando aplicar cada estilo, com quem e em que circunstâncias e tarefas a serem desenvolvidas.

\section{Liderança como competência essencial}

É importante ressaltar que a liderança não é apenas uma habilidade, mas antes disso, uma competência. Competência é o conjunto de conhecimentos (saber), habilidades (fazer) e atitudes (ser) necessárias à realização de uma atividade para que a mesma tenha sucesso. Nesse sentido, o líder, independentemente da área em que atua, deve conhecer sobre a mesma (neste estudo, a área de restaurantes) e ter as habilidades necessárias para exercer o cargo de gerente (metodologias e ferramentas de gestão, por exemplo) (MAXIMIANO, 2000).

Mas, especialmente no caso de um líder, deve também ter um conjunto de atitudes adequadas e condizentes com o seu papel, como honestidade, transparência, equidade, respeito, capacidade de reconhecer e valorizar, entre outras. Neste sentido, o presente artigo trata das competências necessárias ao profissional em posição de liderança, especialmente os gerentes, portanto, de competências humanas. Apesar disso, é importante ressaltar que o aprimoramento dessas competências individuais é essencial para o aprimoramento das competências organizacionais, como ressalta COVEY (1989), segundo o qual, a mudança ou aprimoramento da empresa inicia com a mudança ou aprimoramento do indivíduo.

\section{Macroergonomia e liderança: Pontos de Convergência}

Frequentemente, amplas melhorias na saúde, na segurança, e na produtividade são possíveis quando uma aproximação macroergonômica é realizada (HENDRICK, 2003).

Em termos ergonômicos, as atividades realizadas no ambiente de um restaurante resultam em carga de trabalho principalmente de ordem física. Duarte et al (2002) apontam problemas como esforços físicos e posturas prolongadas relacionadas ao levantamento de carga e posturas assumidas pelos colaboradores na execução de tarefas em diferentes setores, movimentação de panelas e carga sem dispositivo de apoio.

A participação voluntária por parte dos trabalhadores ao longo de todo o trabalho de estudo 
ergonômico é condição necessária para o sucesso da pesquisa. Essa participação do trabalhador tanto na fase de identificação dos constrangimentos ergonômicos, quanto na fase de concepção e das implementações das propostas projetais se justificam, uma vez que garante um maior envolvimento por parte dos mesmos e como consequência gera maior índice de sucesso nas modificações.

Mas, além dos aspectos puramente ergonômicos, os restaurantes muitas vezes se defrontam com desafios de ordem organizacional, e em especial na área de gestão, sendo as questões ligadas ao relacionamento humano frequentes neste setor, conforme foi verificado no presente estudo. Neste estudo, portanto, o objetivo não é a melhoria ergonômica de postos de trabalho ou afins, mas o aprimoramento de aspectos relativos ao desempenho da atividade gerencial, tendo as visões do gerente e dos funcionários como ponto de partida para um diagnóstico dos problemas existentes.

\section{Metodologia}

O estudo de caso foi realizado em um restaurante tipo self-service na região central do município de Londrina-PR, durante o primeiro semestre de 2012. A metodologia utilizada subdividiu-se em quatro etapas e pode ser classificada quanto aos procedimentos como pesquisa de campo, quanto à forma de abordagem como quantitativa e quanto aos objetivos como descritiva.

- Etapa 1 - Avaliação Preliminar do Ambiente de Trabalho: A primeira etapa do estudo consistiu no levantamento das características do ambiente de trabalho, através da observação da atuação do Líder e dos colaboradores no desempenho de suas atividades, bem como, as formas como ambos interagem a fim de atender suas necessidades e objetivos.

- Etapa 2 - Desenvolvimento do Questionário: A avaliação preliminar subsidiou o desenvolvimento do questionário aplicado os funcionários e ao Líder, o qual contém 25 questões. O questionário teve a finalidade de corroborar as características observadas na primeira etapa do estudo, avaliar a satisfação dos colaboradores quanto a gerencia do Líder e verificar o reconhecimento pelo Líder das fraquezas de sua gestão. As questões abrangeram as três dimensões necessárias (conhecimentos, habilidades e atitudes) para a competência em liderança.

- Etapa 3 - Entrevistas: As entrevistas tiveram a finalidade de verificar a satisfação e a insatisfação dos colaboradores frente à gestão do Líder e tiveram duração de 10 a 20 minutos, sendo realizadas no intevalo do expediente. Durante a entrevista os colaboradores foram instruídos sobre como responder os questionários e avisados de que as respostas seriam mantidas em sigilo. Considera-se que esta medida é de grande relevância, pois garante que as respostas dos colaboradores não sejam influenciadas pela insegurança e pelo medo de consequências futuras de suas eventuais críticas.

- Etapa 4 - Levantamento das falhas no campo da macroergonomia: Por fim, a pesquisa de campo possibilitou o levantamento das falhas organizacionais e infraestruturais do ambiente de trabalho no ambito da macroergonomia. O levantamento é indispensável, pois permite a verificação das melhorias que devem ser executadas para melhorar o conforto, a saúde, a segurança e o desempenho dos funcinários no desempenho de suas atividades.

\section{Resultados e Discussão}

\section{Posição e função do líder estudado na estrutura hierárquica}

O organograma da empresa à qual o restaurante (objeto deste estudo de caso) pertence, está apresentado na Figura 1. A rede de restaurantes é composta por sete unidades, distribuídas em diversos locais do município de Londrina. Neste estudo, foi avaliado exclusivamente o desempenho do Gerente 1 e os questionários foram aplicados apenas na Unidade 1, localizada na região central do município. O gerente possui autonomia na tomada das decisões administrativas e participativa ativamente das questões financeiras da unidade, juntamente com o departamento financeiro. 
A macroergonomia na melhoria das condições de ... liderança: Estudo de caso com AMT em um restaurante

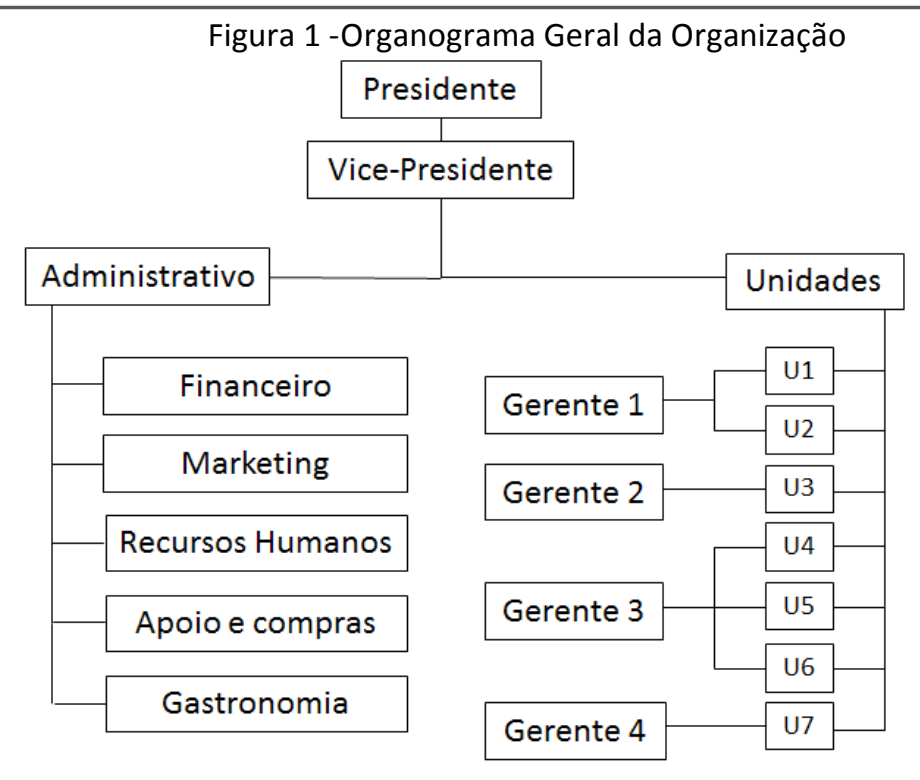

\section{Avaliação preliminar do ambiente de trabalho}

Inicialmente, foi realizada uma analise do local de estudo, no que tange à gerência do lider, as condições de trabalho dos colaboradores e a relação entre os colaboradores e o líder (Tabelas 1 e 2). Esta avaliação preliminar teve a finalidade de verificar os principais temas e aspectos que deveriam ser abordados no questionário. A observação do ambiente de trabalho em foco neste estudo possibilitou viasualizar algumas características do Líder, que devem ser corroboradas com base nos resultados dos questionários.

Tabela 1- Caracteristicas do Líder no ambiente de trabalho

\begin{tabular}{l}
\hline \multicolumn{1}{c}{ Características } \\
\hline Não é bom ouvinte \\
\hline Dificuldade em enxergas suas falhas e defeitos \\
\hline Não considera a opinião dos colaborados na tomada de decisão \\
\hline Os colaboradores tem a liberdade para exporem suas opiniões, mas são desconsideradas \\
quando divergem com as opiniões do Líder. \\
\hline Resistência às mudanças e inovações \\
\hline Não está aberto ao diálogo \\
\hline Não se preocupa com o bem-estar do colaborador no ambiente de trabalho \\
\hline Dificuldade em delegar tarefas e responsabilidades \\
\hline Ausência de encorajamento aos colaboradores \\
\hline Constantes mudanças de opnião \\
\hline $\begin{array}{l}\text { Apresenta a tendência de impor sua autoridade sobre os demais para que suas opiniões e } \\
\text { pontos de vista prevaleçam }\end{array}$ \\
\hline Age da forma mais conveniente para atingir seus objetivos \\
\hline Delega uma nova função ao funcionário, não promove o treinamento do mesmo e cobra \\
resultados à curto prazo
\end{tabular}


Souza, Juliana de; Pereira, Cláudio Sampaio

Tabela 2 - Características dos colaboradores no ambiente de trabalho

\begin{tabular}{l}
\hline \multicolumn{1}{c}{ Características } \\
\hline Colaboradores desmotivados \\
\hline Falta de união e comprometimento dos colaboradores \\
\hline Falta de Comunicação no ambiente de trabalho \\
\hline Dificuldade em atender as necessidades dos clientes \\
\hline Acreditam que seus desempenhos não são reconhecidos pelo Líder \\
\hline Reconhecem que suas opiniões são desconsideradas na tomada de decisão \\
\hline Não reconhecem o Líder como um exemplo a ser seguido \\
\hline Resistência ao desempenho de novas funções \\
\hline Os colaboradores mostram-se desinteressados em participar da resolução de problemas \\
\hline São respeitados pelo Líder
\end{tabular}

Muitas das características verificadas na observação preliminar puderam ser corroboradas ao longo deste estudo, através da comparação entre os resultados dos questionários e a autoavaliação do Líder quanto à sua gerência.

Avaliação da Satisfação e Insatisfação dos colaboradores perante a gerência do Líder

A Tabela 3 apresenta a relação das questões que compõe o questionário aplicado na área de estudo e os resultados obtidos.

Tabela 3 - Questionário e Resultados obtidos.

\begin{tabular}{|c|c|c|c|c|}
\hline & \multirow{2}{*}{ Questక̄o } & \multicolumn{3}{|c|}{ Respostas } \\
\hline & & SA & $\mathbb{I N}$ & ID \\
\hline 1 & Valoriza os colaboradores & 3 & 9 & 2 \\
\hline 2 & $\begin{array}{l}\text { Confronta os colaboradores com problemas/situaçð̄es à medida } \\
\text { que surgem }\end{array}$ & 8 & 6 & 0 \\
\hline 3 & $\begin{array}{l}\text { Circula durante bastante tempo na área de trabalho e acompanha } \\
\text { as atividades dos subordinados }\end{array}$ & 8 & 6 & 0 \\
\hline 4 & Estimula es colaboradores & 5 & 8 & 1 \\
\hline 5 & Deixa claro para os colaboradores o que espera deles no trabalho & 8 & 6 & 0 \\
\hline 6 & E um bom cuvinte & 5 & 9 & 0 \\
\hline 7 & $\begin{array}{l}\text { Treina e aconselha os colaboradores para garantir que os } \\
\text { objetivos serz̃oalcançados }\end{array}$ & 4 & 9 & 1 \\
\hline 8 & Trata os colaboradores com respeito & 12 & 2 & 0 \\
\hline 9 & Participa ativamente do desenvolvido dos colaboradores & 3 & 11 & 0 \\
\hline 10 & $\begin{array}{l}\text { Atribui responsabilidades aos colaboradores para que alcancem } \\
\text { es padröes determinados }\end{array}$ & 8 & 6 & 0 \\
\hline 11 & Atribui crédito a quem merece & 3 & 11 & 0 \\
\hline 12 & Demonstra paciência e auto-controle com os colaboradores & $\mathbf{5}$ & 9 & 0 \\
\hline 13 & Os colaboradores sentem-se confiantes em segui-lo & 3 & 10 & 0 \\
\hline 14 & Possui as habilidades técnicas necessárias para o cargo & 3 & 11 & 0 \\
\hline 15 & Atende as legitimas necessidades dos colaboradores & 3 & 11 & 0 \\
\hline 16 & E capaz de perdoar erros e não guarda ressentimentos & 10 & 4 & 0 \\
\hline 17 & Transmite confiança acs colaboraderes & 10 & 4 & 0 \\
\hline 18 & Age com boa indole perante os colaboradores & 10 & 4 & 0 \\
\hline 19 & Dá feedbock positivo acs colaboradores & 8 & 6 & 0 \\
\hline 20 & $\begin{array}{l}\text { Nào embaraça e/ou pune os colaboradores na presença de } \\
\text { clientes e demais funcionários }\end{array}$ & 6 & 8 & 0 \\
\hline 21 & $\begin{array}{l}\text { Fixam objetivos elevados para sua gerência, para os subordinados } \\
\text { e para o departamento. }\end{array}$ & 5 & 9 & 0 \\
\hline 22 & Tem uma atitude positiva no cargo. & 10 & 4 & 0 \\
\hline 23 & $\begin{array}{l}\text { É sensivel às conseqüências de suas decisōes para os outros } \\
\text { departamentos. }\end{array}$ & 3 & 11 & 0 \\
\hline 24 & E um lider justo e coerente, liderando pelo exemplo. & 4 & 10 & 0 \\
\hline 25 & Não é um lider excessivamente controlador ou dominador. & 6 & 8 & 0 \\
\hline
\end{tabular}

SA: Satisfeitos; IN: Insatisfeitos; ID: Indecisos. 
A macroergonomia na melhoria das condições de ... liderança: Estudo de caso com AMT em um restaurante

Na Figura 1 encontra-se ilustrada a distribuição das respostas dos colaboradores, inclusos na pesquisa, para cada uma das 25 questões contidas no questionário, no que se refere à satisfação e à insatisfação dos colaboradores frente a gerência.

Figura 1-Distribuição das respostas do questionário.

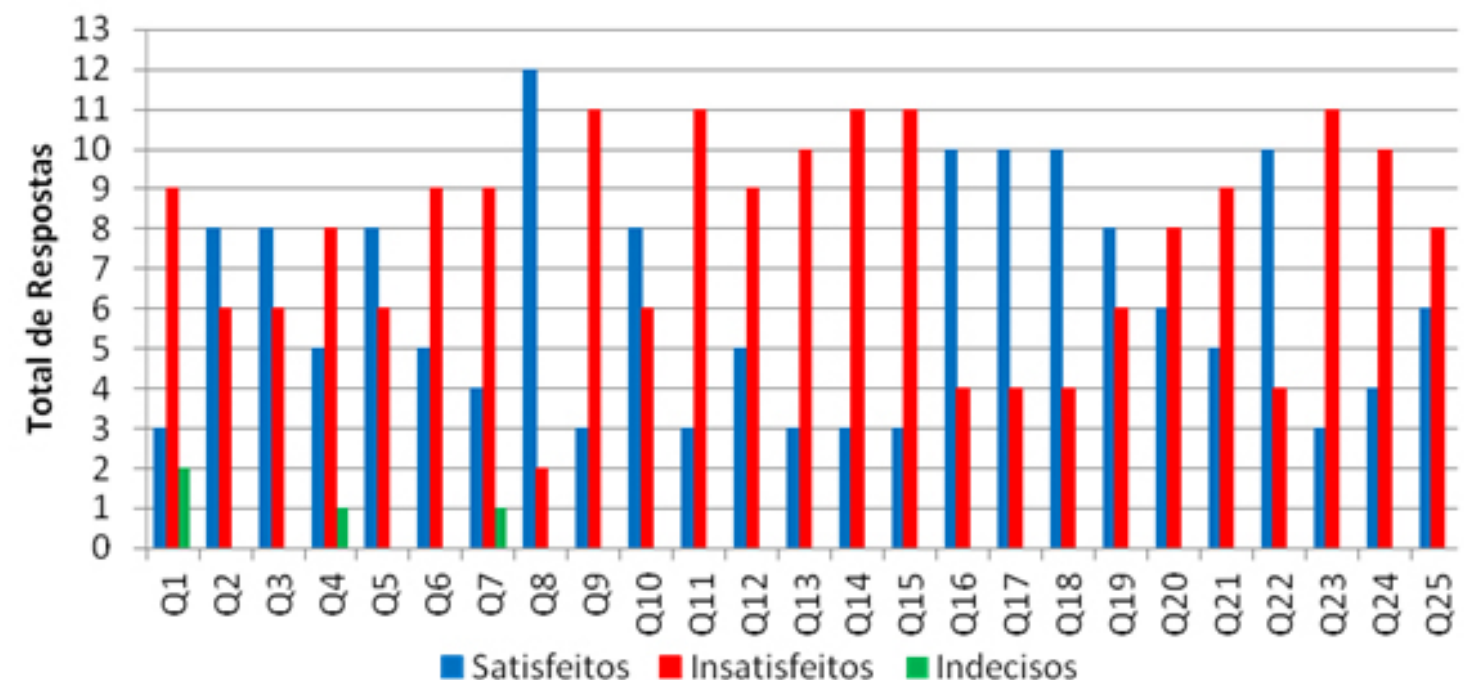

Na Figura 2(A) e 2(B) encontram-se ilustradas a distribuição geral das respostas dos questionários em termos do Total de Respostas e em Termos Percentuais, respectivamente. Observase um equilíbrio entre o número total de respostas"Satisfeito" e "Insatisfeito", sendo que o primeiro representa um total de 153 respostas (55\%) e o segundo, 192 respostas (44\%). Apenas $1 \%$ das respostas dos entrevistados foram consideradas nulas e, consequentemente, caracterizadas como "Indecisos".

Figura 2 -Distribuição geral das respostas dos questionários em termos do total de respostas (A) e Percentuais (B).

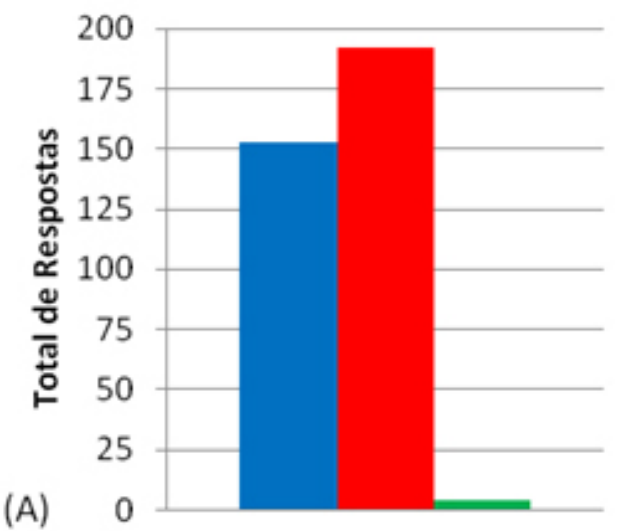

[ Satisfeitos $\mathbf{m}$ Insatisfeitos $\mathbf{m}$ Indecisos

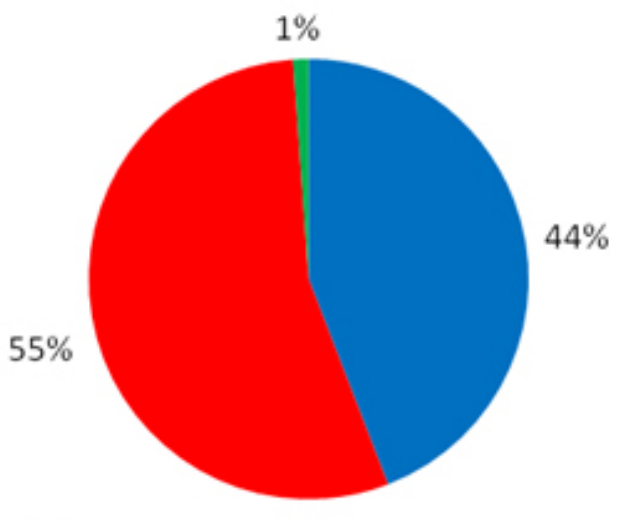

(B)

— Satisfeitos $\mathbf{m}$ Insatisfeitos $\mathbf{m}$ Indecisos

Os Gráficos de Pareto para a distribuição das respostas dos colaboradores satisfeitos e insatisfeitos estão apresentados na Figura 3 e na Figura 4. Estes recursos Gráficos permitem a ordenação em ordem decrescente dos resultados de cada uma das 25 questões que compõe o questionário. 


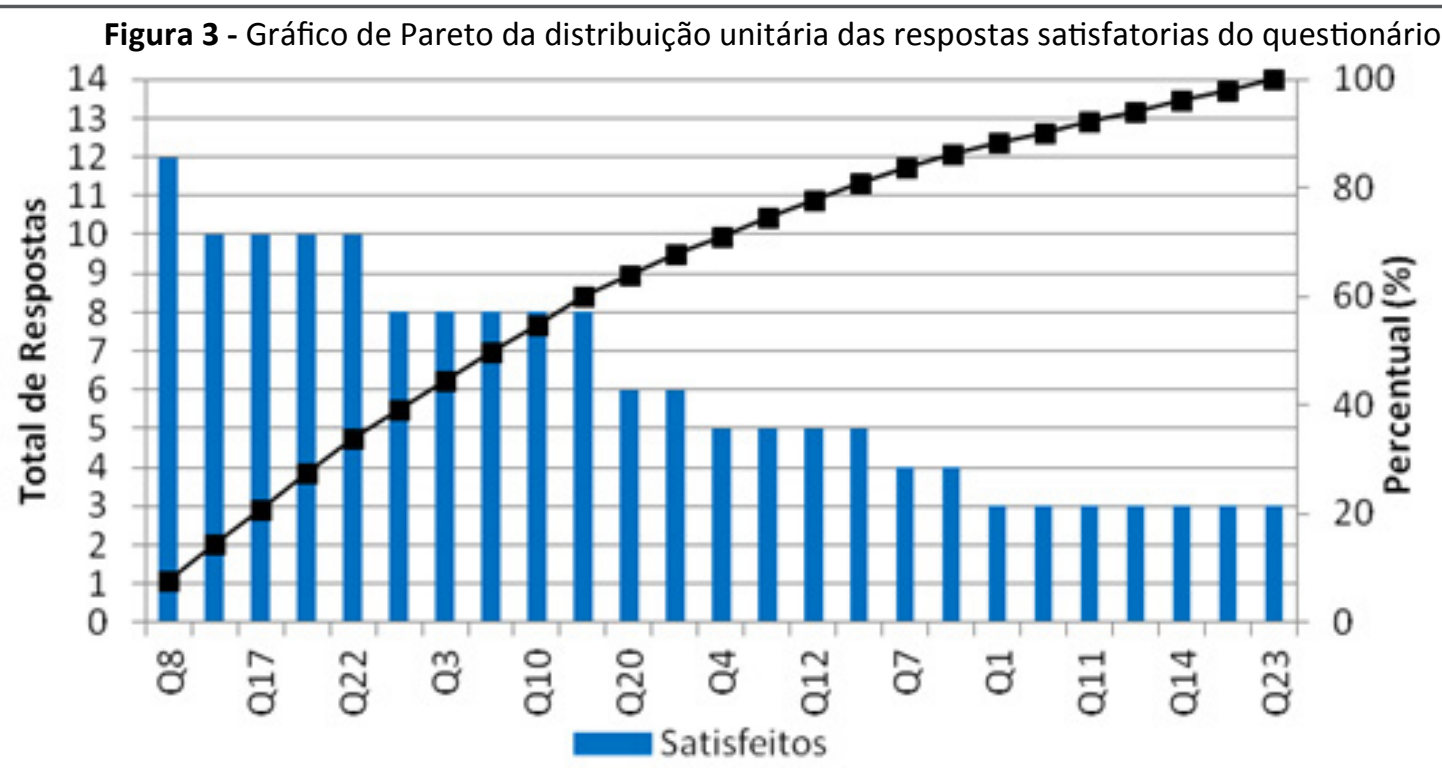

Na Figura 03 observa-se que os pontos fortes do Líder, em foco no presente estudo, são aqueles abordados pelas questões Q8, Q16, Q17, Q18 e Q22, tendo uma aprovação de mais de 10 dos 14 entrevistados (aprovação de aproximadamente $71 \%$ dos colaboradores em cada questão). 0 resultado do questionário demostra que os pontos fortes do gerente, na visão dos colaboradores, envolvem características como:

- Respeito clientes e funcionários;

- Não guarda resentimentos por erros cometidos;

- É uma pessoa leal e transmite confiança;Age com boa índole no desempenho de suas funções;

- Tem bom desempenho na função que exerce.

Figura 4 - Gráfico de Pareto da distribuição unitária das respostas insatisfatorias do questionário.

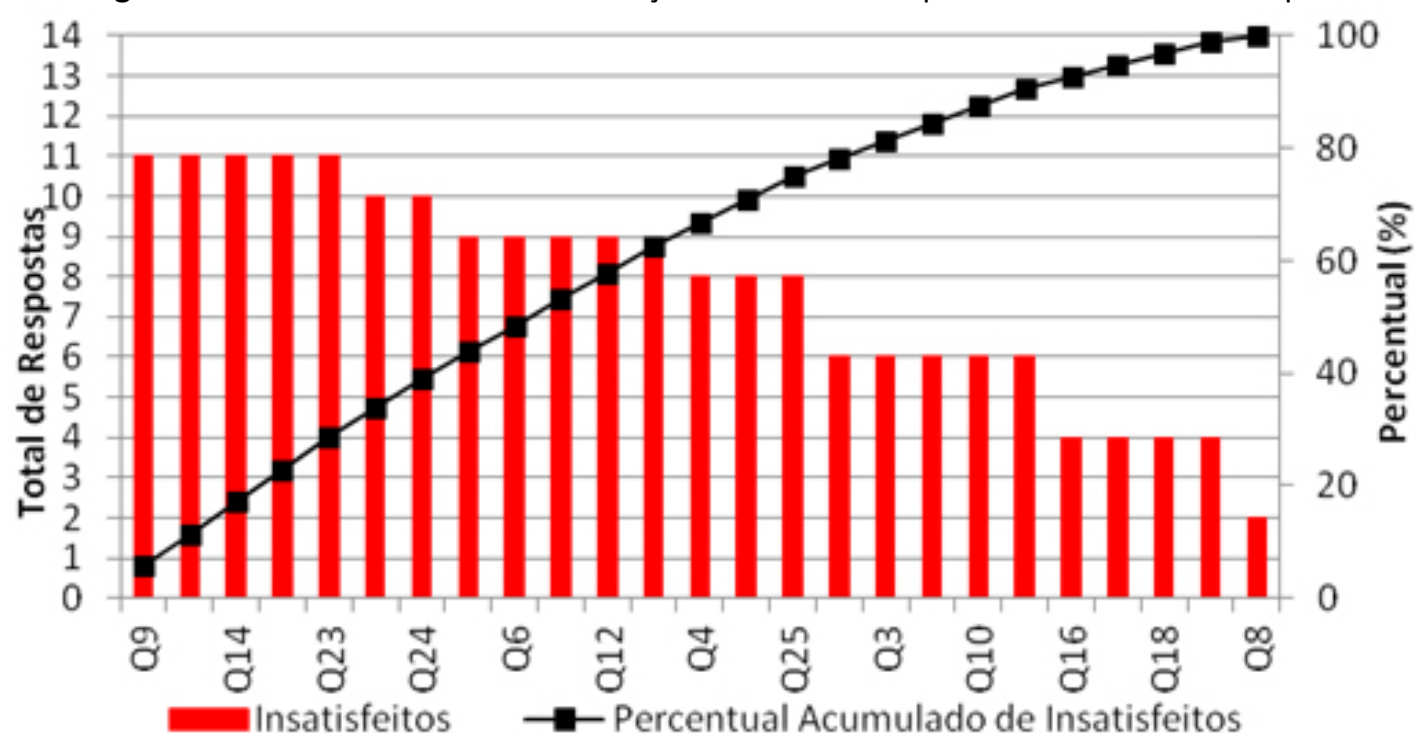

A Figura 4 permite visualizar que as fraquezas principais na gestão do Líder, apontadas pelos colaboradores, estão relacionadas com os temas abordados pelas questões Q9, Q11, Q14, Q15, Q23, Q13 e Q24, tendo alcançado a satisfação de igual ou superior a 10 funcionários dos 14 que participaram 
A macroergonomia na melhoria das condições de ... liderança: Estudo de caso com AMT em um restaurante

da pesquisa. Isto representa uma reprovação, de aproximadamente $71 \%$ dos colaboradores em cada uma das questões. O resultado do questionário demostra que os pontos fracos do gerente, na visão dos colaboradores, envolvem principalmente as seguintes características:

- Interesse e participação ativa no desenvolvimento dos colaboradores;

- Distribuição de créditos e elogios pelo bom desempenho;

- Habilidades Técnicas necessárias para o cargo;

- Coerência e justiça na Liderança;

- Alienação quanto às consequências de sua gerência em outros departamentos;

- Transmite confiança aos colaboradores.

A Tabela 4 apresenta as questões que apresentaram maior número de respostas satisfatórias e, por conseguinte, os quesitos nos quais os colaboradores estão mais satisfeitos quanto a gerencia do Líder. Estes quesitos representam os pontos fortes da gerência.

Tabela 4 - Pontos Fortes da gerência do Líder

\begin{tabular}{ccccc}
\hline Questão & $\begin{array}{c}\text { Colaboradores } \\
\text { Satisfeitos } \\
\text { (total) }\end{array}$ & $\begin{array}{c}\text { Colaboradores } \\
\text { Insatisfeitos } \\
\text { (total) }\end{array}$ & $\begin{array}{c}\text { Colaboradores } \\
\text { Indecisos } \\
\text { (total) }\end{array}$ & $\begin{array}{c}\text { Colaboradores } \\
\text { Satisfeitos (\%) }\end{array}$ \\
\hline Q8 & 12 & 2 & 0 & 85,71429 \\
\hline Q16 & 10 & 4 & 0 & 71,42857 \\
\hline Q17 & 10 & 4 & 0 & 71,42857 \\
\hline Q18 & 10 & 4 & 0 & 71,42857 \\
\hline Q22 & 10 & 4 & 0 & 71,42857 \\
\hline
\end{tabular}

A Tabela 5, por sua vez, apresenta as questões que apresentaram maior número de respostas insatisfatórias e representam os quesitos nos quais os colaboradores estão menos satisfeiros quanto à gerencia do Líder. Estes quesitos representam as fraquezas da gerencia.

Tabela 5 -Fraquezas da gerência do Líder

\begin{tabular}{ccccc}
\hline Questão & $\begin{array}{c}\text { Colaboradores } \\
\text { Satisfeitos } \\
\text { (total) }\end{array}$ & $\begin{array}{c}\text { Colaboradores } \\
\text { Insatisfeitos } \\
\text { (total) }\end{array}$ & $\begin{array}{c}\text { Colaboradores } \\
\text { indecisos } \\
\text { (total) }\end{array}$ & $\begin{array}{c}\text { Colaboradores } \\
\text { Insatisfeitos } \\
\text { (\%) }\end{array}$ \\
\hline Q9 & 3 & 11 & 0 & 78,57142857 \\
\hline Q11 & 3 & 11 & 0 & 78,57142857 \\
\hline Q14 & 3 & 11 & 0 & 78,57142857 \\
\hline Q15 & 3 & 11 & 0 & 78,57142857 \\
\hline Q23 & 3 & 11 & 0 & 78,57142857 \\
\hline Q13 & 3 & 10 & 0 & 76,92307692 \\
\hline Q24 & 4 & 10 & 0 & 71,42857143 \\
\hline
\end{tabular}

\section{Comparação entre os resultados dos questionários e a autoavaliação do Líder}

A fim de avaliar a relação entre o líder e os colaboradores, bem como, a comuniacação entre ambos, os resultados obtidos pela apliacação dos questionários foi comparada com a autoavaliação do 
Souza, Juliana de; Pereira, Cláudio Sampaio

Líder com realação aos pontos fortes e fracos de sua gestão. A comparação está ilustrada na Tabela 6.

Tabela 6 - Comparação dos resultados do questionário com a autoavaliação do Líder

\begin{tabular}{|c|c|c|c|c|}
\hline \multirow{2}{*}{ Questão } & \multicolumn{3}{|c|}{ Colaboradores } & \multirow{2}{*}{ Lider } \\
\hline & Satisfeitos & Insatisfeitos & Indecisos & \\
\hline Q1 & 3 & 9 & 2 & Indeciso \\
\hline Q2 & 8 & 6 & 0 & Satisfeito \\
\hline Q3 & 8 & 6 & 0 & Satisfeito \\
\hline Q4 & 5 & 8 & 1 & Satisfeito \\
\hline Q5 & 8 & 6 & 0 & Indeciso \\
\hline Q6 & 5 & 9 & 0 & Satisfeito \\
\hline Q7 & 4 & 9 & 1 & Insatisfeito \\
\hline Q8 & 12 & 2 & 0 & Satisfeito \\
\hline Q9 & 3 & 11 & 0 & Satisfeito \\
\hline Q10 & 8 & 6 & 0 & Indeciso \\
\hline Q11 & 3 & 11 & 0 & Satisfeito \\
\hline Q12 & 5 & 9 & 0 & Satisfeito \\
\hline Q13 & 3 & 10 & 0 & Indeciso \\
\hline Q14 & 3 & 11 & 0 & Satisfeito \\
\hline Q15 & 3 & 11 & 0 & Satisfeito \\
\hline Q16 & 10 & 4 & 0 & Satisfeito \\
\hline Q17 & 10 & 4 & 0 & Satisfeito \\
\hline Q18 & 10 & 4 & 0 & Satisfeito \\
\hline Q19 & 8 & 6 & 0 & Satisfeito \\
\hline Q20 & 6 & 8 & 0 & Satisfeito \\
\hline Q21 & 5 & 9 & 0 & Indeciso \\
\hline Q22 & 10 & 4 & 0 & Satisfeito \\
\hline Q23 & 3 & 11 & 0 & Satisfeito \\
\hline Q24 & 4 & 10 & 0 & Indeciso \\
\hline Q25 & 6 & 8 & 0 & Insatisfeito \\
\hline
\end{tabular}

A análise da Tabela 6 torna perceptível a presença de incoerrências entre a avaliação dos colaboradores e a auto-avaliação do Líder frente aos pontos fortes e fracos da gerência. Nos temas abordados nas questões Q6, Q9, Q11, Q12, Q14, Q15 e Q23 o Líder considerou-se satisfeito com sua gestão, contudo, nestas mesmas questões, a porção majoritária dos coladoradores mostrou-se insatisfeita.

Estas divergências na avaliação da gerência podem ser resultado de dois fatores:

- Comunicação limitada ou inexistente entre colaboradores e gerente;

- Não reconhecimento das falhas na gerência pelo Líder, apesar da comunicação das insatisfações dos colaboradores. 


\section{Proposições de melhoria com base nos problemas detectados}

Partindo-se do presuposto de que o processo de substituição do Líder, em consequência de suas eventuais falhas, inabilidades e incapacidades, é uma opção apenas em último caso, a seguir estão listadas algumas medidas que podem e devem ser tomadas pelo Líder para que sua gestão seja melhorada. Foram selecionados os quesitos abordados nas questões Q9, Q11, Q13, Q14, Q15, Q23 e Q24, que representam os principais pontos fracos da gerência do Líder, conforme verificado na aplicação dos questionários e apresentado na Tabela 5. As questões estão dispostas em ordem decrescente de importancia, na qual a questão Q9 recebeu o maior número de críticas por parte dos colaboradores.

Vale ressaltar que o apoio da alta direção, no que tange ao reconhecimento das falhas apontadas pelos colaboradores e do apoio aos esforços do líder no processo de melhoria dos diversos aspectos de sua gestão, é indispensável. A alta direção deve fornecer os recursos necessários para esse processo de melhoria e fiscalizar para que este seja devidamente planejado, realizado e implantado.

\section{Q9 - Participa ativamente do desenvolvimento dos colaboradores.}

- Promover o estreitamento da relação colaborador-líder é uma importante medida para verificar quais as falhas apresentadas pelos trabalhadores no desempenho de suas atividades e uma valiosa oportunidade de participar o desenvolvimento das habilidades dos funcionários, através de aconselhamentos, ensinamentos e alertas.

- Quando as limitações técnicas do colaborador restringem o desenvolvimento de suas habilidades no cargo, o gerente deve estar atento para determinar quais as medidas mais adequadas para cada caso. $\mathrm{O}$ Líder pode opitar, dentro das realidades e das necessidades da empresa, promover o remanejamento do trabalhador ou a inserção do mesmo em cursos de capacitação.

- O monitoramento da evolução do desempenho do trabalhador, através de dados e recursos visuais, permite a visualização dos pontos falhos e dos pontos fortes do trabalhador. Esta medida permite verificar em quais quesitos os esforços devem ser concentrados para a melhoria do desempenho.

\section{Q11 - Atribui crédito a quem merece.}

- A distribuição de elogios e parabenizações aos funcinários que atinjam suas metas ou apresentem melhorias em seus pontos falhos, apesar de uma medida simples e sem custos financeiros pode ter grande impacto sobre a produtividade e sobre o desempenho dos colaboradores. Estes se sentem reconhecidos pelos seus esforços e percebem que são visualizados como elementos-chave na estrutura organizacional do estabelecimento.

- Desenvolvimento de um sistema de premiação para os trabalhadores que se destacarem pelo atendimento das metas e pela excelência funcional. As premiações não devem ser apenas financeiras, mas explorar outras formas de benefícios aos colaboradores. Porém, é necessário prudência nesta iniciativa, para que a excelência operacional dos funcionários não fique condicionada à concessão de prêmios e benefícios.

\section{Q14 - Possui habilidades técnicas necessárias para o cargo.}

- O reconhecimento da falta de habilidade técnica para o cargo é o primeiro passo para que o Líder melhore sua gerência. Esta constatação pode fazer com que ele reflita acerca da necessidade de desenvolver as habilidades técnicas para o cargo e para que tenham maior disposição para aceitar a opinião dos envolvidos no ambiente de trabalho.

- A capacitação e o treinamento, mediante a participação de cursos, palestras e outras atividades, é o principal mecanismo pelo qual o gerente pode adquirir as capacidades técnicas para o desempenho adequado da função de gerente e líder.

\section{Q15 - Atende as legítimas necessidades dos colaboradores.}

- O Líder deve possuir discernimento para reconhecer quais as solicitações dos colaboradores são verdadeiramente legítimas e atendê-las. As demandas de ferramentas e maquinários, indispensáveis para o desempenho adequado das atividades dos funcionários, são quse sempre deixadas em segundo 
plano, causando a desmotivação dos mesmos.

- O estabelecimento de um sistema de comunicação formal e não apenas verbal para as solicitações diárias dos colaboradores é uma importante medida. Este sistema permite o levantamento de todas as necessiadades dos funcionários sob a gestão do Líder e priorizá-las de acordo com a relevância, bem como, comprovar que a solicitação foi devidamente entregue ao responsável. O tipo de sistema mais adequado varia de acordo com a realidade financeira e infraestrutural da organização.

\section{Q23 - É sensível às consequências de suas decisões para os outros departamentos.}

- Profundo conhecimento do organograma da empresa. O organograma não apresenta apenas a hierarquia da organização, mas também possibilita visualizar os departamentos e funcionários sobre comando do Líder e, consequentemente, aqueles impactados por suas decisões, falhas e acertos. Vale ressaltar que os diversos departamentos que compõe a organização são interligados e interdependentes. Dessa forma, as decisões do Líder em um departamento afetam outros setores que não estão sob seu comando.

- A criação e a manutenção de um canal eficiente e ativo para a comunicação entre os departamentos representa uma importante medida, já que permite, em tese, a verificação do impacto das decisões do Líder em outros departamentos.

Q13 - Os colaboradores sentem-se confiantes em segui-lo.

- O estreitamento da relação colaborador-líder e o desenvolvimento das habilidades técnicas para a liderança naturalmente resultam no aumento da confiança dos colaboradores frente às ideias e decisões do Líder.

- O Líder expor aos colaboradores quais os motivos que o levaram a tomar determinada decisão em detrimento de outra. Conhecendo as motivações do Líder e suas perpectivas, eles podem compreender quais os motivos que o levaram a tomar essa decisão. É importante, também, expor os benefícios que podem ser alcançados.

Q24 - É um Líder justo e coerente, liderando pelo exemplo.

- O gerente ou gestor deve reconhece-se não apenas como o Líder da organização ou do setor, mas também como o exemplo a ser seguido. Todas as regras e deveres instituidos ao conjunto de trabalhadores devem, em geral, ser também aplicadas ao Líder. Através disso, é transmitida a informação aos colaboradores de que ninguém está alheio aos deveres para com a organização. Além disso, o Líder pode demonstrar na prática as melhorias geradas pela mudança de hábitos e eliminação dos vícios.

- Para garantir a boa relação colaborador-líder, o Líder deve ter coerência e justiça em sua gestão. Ele deve apontar as falhas e o mal desempenho de um funcionário, mas também incentivar, orientar e parabenizar quando o desempenho for melhorado. Dessa forma, os colaboradores visualizam o Líder como não como um carrasco, mas como um parceiro na melhoria de seus desempenhos.

\section{Liderança e Macroergonomia: pontos de convergência}

Frequentemente, amplas melhorias na saúde, na segurança, e na produtividade são possíveis quando uma aproximação macroergonômica é realizada (HENDRICK, 2003). O reconhecimento destas possibilidades por parte do Líder é indispensável para a implementação dos conceitos, ferramentas e iniciativas abordadas pela Macroergonomia. Este reconhecimento é possivel quando o gerente apresenta as características necessárias para realizar uma boa liderança.

O Líder analisado neste estudo dificilmente conseguirá visualizar os benefícios gerados pela melhoria das condições de saúde e segurança para os trabalhadores, previstas na Macroergonomia, na melhoria do bem-estar e da produtividade dos colaboradores, já que ele apresenta dificuldade em reconhecer suas falhas e apresenta a tendencia de desconsiderar as opiniões, necessidades e solicitações dos funcionários sob sua gerência.

Porém, a adoção das medidas mensionadas no item 8.5 e de outras iniciativas surgem como 
A macroergonomia na melhoria das condições de ... liderança: Estudo de caso com AMT em um restaurante

um caminho promissor. Neste sentido, pode-se perceber como a liderança nos estabelecimentos é crucial para a macroergonomia. Duas temáticas, aparentemente distintas e desconexas, nada mais são que complementares e interligadas.

Dentre as características do Líder, verificadas através do questionário, que impedem ou dificultam a visualização das melhorias que devem ser realizadas no campo da Macroergonomia, destacam-se:

- Tendência em desconsiderar as necessidades e solicitações dos colaboradores;

- Não é sensível às consequências de suas deisões para os outros departamentos;

- Tendência em utilizar sua autoridade para impor sua opinião sobre as dos colaboradores;

- Não é bom ouvinte.

Contudo, algumas de suas características são importantes no que tange a aplicação da Macroergonomia em seu ambiente de trabalho, dentre as quais:

- Confronta os colaboradores com situações-problema à medida que surgem;

- Circula durante bastante tempo na área de trabalho e acompanha as atividades dos colaboradores.

A pesquisa de campo permitiu o levantamento de algumas falhas na estrutura organizacional e infraestrutural do ambiente de trabalho, no campo da macroergonomia, que devem ser melhoradas a fim de aumentar o conforto, a saúde, a segurança e o desempenho dos colaboradores no desempenho de suas atividades profissionais.

\section{Discussão dos resultados}

Os resultados dos questionários indicam que o líder não possui as características adequadas para o desempenho de uma boa gestão e liderança. Os funcionários consideram que o líder tem como pontos fracos o pouco interesse e participação no desenvolvimento dos colaboradores, ausência ou baixa distribuição de créditos pelo bom desempenho, inabibilidade técnica para o desempenho da função, incorência na Liderança, alineação quanto às consequências de suas decisões aos demais departamentos e setores da organização, bem como, pouca transmissão de confiança aos colaboradores.

Além disso, algumas características do Líder, como ser um mau ouvinte e impor sua autoridade sobre as opinião dos demais, dificultam ainda mais o desempenho de uma gestão e liderança adequada pelo mesmo. Esta realidade é corroborada pela incompatibilidade entre as respostas dos questionários do Líder e dos colaboradores. Em diversas questões o Líder encontrava-se satisfeito com seu desempenho, mas os funcinários mostravam-se insatisfeitos. Para que o Líder consiga solucionar as falhas e limitações apontadas pelos colaboradores é indispensável a manutenção de uma comunicação constante, mantendo-se atento às necessidades e dificuldades dos empregados.

Aparentemente, o líder não demonstra nenhuma intensão de melhorar o desempenho de sua gerência por negligência ou por desconhecimento dos seus pontos falhos. Como a divergência entre a autoavaliação do lider e a avaliação dos colaboradores foi grande, há um indicativo que o gerente realmente não reconhece seus pontos falhos, porém, apenas a realização de um estudo mais aprofundado pode subsidiar uma afirmação concreta e indiscutível.

\section{Conclusão}

Através do estudo foi possível concluir que o desempenho de uma boa gerência e liderança requer características indispensáveis, não bastanto exercer o papel de líder no organograma da empresa. O líder deve ter uma relação de respeito, diálogo e ajuda mútua com os colaboradores, 
mantendo o comprometimento para a melhoria contínua do ambiente de trabalho, do conforto dos clientes e trabalhadores.

O estudo permitiu verificar como a macroergonomia está intimamente ligada à liderança. Os conceitos, técnicas e ferramentas da macroergonomia somente podem ser aplicados e implementados em sua plenitude quando são reconhecidos pelo Líder como indispensáveis para o bem-estar dos trabalhadores e para a melhoria do seu desempenho. Para tal, o gerente deve ter os requisitos mínimos para uma boa liderança, manter uma boa relação com os colaboradores e instituir a livre comunicação entre ambos.

Confrontar as opiniões dos colaboradores quanto à gestão do Líder, expressas através dos questionários e das entrevistas, com a autoavaliação do Líder quanto à sua gestão é uma excelente iniciativa para avaliar se o mesmo reconhece os pontos falhos de sua gestão, que é uma etapa crucial para o processo de melhoria e crescimento profissional do Líder.

A abordagem conjunta da liderança e da macroergonomia em restaurantes mostrou-se uma iniciativa válida e útil, pois permitiu verificar que, apesar de aparentemente distintas, ambas são complementares no ambiente de trabalho. Os conceitos e iniciativas voltadas para a macroergonomia somente podem ser aplicados em sua plenitude em restaurantes se o líder reconhece os benefícios que podem ser gerados aos colaboradores e para a organização. Neste sentido, as habilidades e requisitos mínimos para o desempenho de uma boa liderança por parte do gerente é indispensável.

Dentre as limitações verificadas no presente estudo a que mais se destaca é a ausência de um levantamento aprofundado das reivindicações dos colaboradores quanto à melhoria do ambiente de trabalho, tendo como foco a macroergonomia. Para tal, seria necessário elaborar um questionário mais detalhado e realizar um acompanhamento dos funcionários que compõe o estabelecimento no desempenho de suas atividades durante seu expediente. A visualização desta realidade torna-se um incentivo para a continuidade das pesquisas voltadas para a temática.

\section{Referências}

AUBERT, N. Leadership. In: AUBERT, N. et al. Management: aspects humains et organisationnels. Paris: Presses Universitaires de France, 1991.

BENNIS, W.G.; MANUS, B. Líderes: Estratégias para Assumir a Verdadeira Liderança. São Paulo: Harbra, 1998.

BERGAMINI, C. W. Liderança: administração do sentido. São Paulo: Atlas, 1994. 234p.

CARBONE, P.P. Desenvolvimento Gerencial: O perfil do Gerente de Agência do BB. 1992. 252p. Dissertação em Administração Pública -Fundação Getúlio Vargas, Rio de Janeiro, 1992.

CASTELO BRANCO, V. R. Gestão por Competências e Habilidades. Disponível em < http://www. administradores.com.br/informe-se/artigos/gestao-por-competencias-e-habilidades/ 46925/> Acesso em 24 de maio de 2012.

CHIAVENATO, I. Gerenciando Pessoas: o passo decisivo para a administração participativa. 2ạ. ed. São Paulo: Makron Books, 1994.

CHIAVENATO, I. Teoria Geral da Administração. 5ạ. ed. Rio de Janeiro: Campus, 1999.

COVEY, S.R. Os sete hábitos das pessoas altamente eficazes. Rio de Janeiro: Best Seller, 2004.

FREEMAN, E. Administración. México: Prentice Hall Hispanoamericana, 1995.

GUIMARAES, L.B.M. Ergonomia de Processo I. 5a ed. Porto Alegre: FEENG/UFRGS/EE/PPGEP, 2006. 436p. 
A macroergonomia na melhoria das condições de ... liderança: Estudo de caso com AMT em um restaurante

HENDRICK, H.W. Determining the cost-benefits of ergonomics projects and factors that lead to their success. Applied Ergonomics, v. 34, n. 5, p.419-427. 2003.

IIDA, I. Ergonomia: projeto e produção. 2a ed. São Paulo: Edgard Blücher, 2005. 630p.

KENNEDY, C. O guia dos gurus do gerenciamento. Rio de Janeiro: Record, 2000. 286p.

KLEINER, B. M. Macroergonomic analysis of formalization in a dynamic work system. Applied Ergonomics: Elsevier Science Ltda, v. 29, n. 4, p. 255-259, 1998.

KOTTER, J.P. Afinal o que fazem os Líderes: A nova face do poder e da estratégia. Rio de janeiro: Campus, 2000.

KOYS, D.; DeCOTIIS, T. Inductive measures of psychological climate. Human Relations, v.44, n.3, p.265-285, 1991.

LIKERT, R. New Patterns of Management. Nova York: McGraw-Hill, 1961.

MAXIMIANO, A.C.A. Teoria geral da administração: da escola cientifica à competitividade na economia globalizada. 2a ed. São Paulo: Atlas, 2000.

MEDEIROS, E. Macroergonomia. Rio de Janeiro: CESERG, 2005.

OLIVEIRA, S. L. Tratado de metodologia científica: projetos de pesquisas, TGI, TCC, monografias, dissertações e teses. São Paulo: Pioneira/ Thomson Learning, 2001.

ROBBINS, S.P. Administração, mudanças e perspectivas. São Paulo: Saraiva, 2000.

ROBBINS, S.P. Comportamento organizacional. São Paulo: Pearson Prentice Hall, 2005.

SISK, L.; SVERDLIK, M. Administración y gerencia de empresas. USA.: South-western Publishing CO, 1979.

SCHERMERHORN Jr., J.R. Administração. 5ạ ed. Rio de Janeiro: LTC, 1999.

YULK ,G.A. Leadership in organizations. USA: Preintice-Hall, 1989. 